\title{
Erratum to: An experimental and numerical study of heat transfer in jacketed vessels by $\mathrm{SiO}_{2}$ nanofluid
}

\author{
Parinaz Hafezisefat $^{1} \cdot$ Mohsen Nasr Esfahany ${ }^{1} \cdot$ Mohammad Jafari $^{2}$
}

Published online: 10 April 2017

(C) Springer-Verlag Berlin Heidelberg 2017

\section{Erratum to: Heat Mass Transfer DOI 10.1007/s00231-017-1989-4}

In the original publication of the article, one author was left out in the list of authors. The correct list should read as follows:

Parinaz Hafezisefat, Mohsen Nasr Esfahany, Mohammad Jafari

Affiliation for the first and second author should read as:

Department of Chemical Engineering, Isfahan University of Technology, Isfahan 8415683111, Iran.

Affiliation for the third author should read as:

Department of Aerospace Engineering, Iowa State University, Ames, IA 50011, USA.

The original publication of the article has been updated to reflect these changes.

The online version of the original article can be found under doi:10.1007/s00231-017-1989-4.

Mohammad Jafari

mjafari@iastate.edu

1 Department of Chemical Engineering, Isfahan University of Technology, Isfahan 8415683111, Iran

2 Department of Aerospace Engineering, Iowa State University, Ames, IA 50011, USA 